J. AMER. SOC. HorT. SCI. 118(2):286-292. 1993.

\title{
Accumulation of the Components of Total Solids in Ripening Fruits of Tomato
}

\author{
T.E. Young, J.A. Juvik, and J.G. Sullivan \\ Department of Horticulture, University of Illinois, Urbana, IL 61801 \\ Additional index words. tomato breeding, quality components, soluble solids, fructose, glucose, Lycopersicon \\ esculentum
}

Abstract. To identify qualitative and quantitative chemical variation in tomato fruit dry matter, crosses were made between the high soluble solids concentration (SSC) line LA 1501 (6.3\% SSC when red-ripe) and the nearly isogenic commercial tomato cultivar VF 145B-7879 with a lower SSC (4.4\% when red-ripe). Fruit samples from the parents and the reciprocal $F_{1}$ hybrids were collected at 3-day intervals, from 25 to 52 days after anthesis, to evaluate the accumulation of various quality components throughout the development of the fruit from immature-green to redripe stage. Fructose and glucose concentrations, titratable acidity, $\mathrm{pH}$, and percent dry weight (pulp and serum) were determined for each sample on a fresh basis. Fruit maturity was evaluated by puree color using Hunter 'a' colorimeter values. Changes in most of the chemical constituents of the fruit were found to regress linearly with changes in fruit color. Regression of puree color against fruit SSC, and fructose, glucose, and total sugar concentrations described more of the observed variability in these components than days after anthesis, indicating that Hunter ' $a$ ' colorimetric values provide a more precise measurement of fruit physiological age. The variation between the parents in fruit dry matter was found to be primarily due to differences in SSC. The ratio of fruit soluble to total solids concentration increased $23.7 \%$ in LA 1501 (from $61.6 \%$ to $85.3 \%$ ) throughout ripening compared to-an increase of only $8.9 \%$ (from $66.3 \%$ to $75.2 \%$ ) in 'VF 145B-7879'. At the red ripe stage, LA 1501 possessed a $44 \%$ higher SSC than 'VF 145B-7879'. Differences in fructose and glucose accounted for $41 \%$ of the variation in SSC between the two lines. An unidentified component(s) was responsible for the residual variation. Application of the genetic and physiological information generated from this study can be used to isolate and select for genes controlling accumulation of tomato fruit dry matter.

Higher fruit total and SSC is of major economic value for the processing tomato industry, since even a small increase can significantly enhance yield and decrease the cost of dehydration of puree into sauce and paste (Rick, 1974). Soluble solids are also of prime concern in fresh market tomato production due to the important contribution that sugars and acids make to the overall flavor of the fruit (Stevens et al., 1977). Davies and Hobson (1981), in their review, estimated that of the water soluble portion of the fruit dry matter, about half is in the form of the reducing sugars fructose $(25 \%)$ and glucose $(22 \%)$. A further quarter of the dry matter consists of citric (9\%), malic (4\%) and dicarboxylic amino acids $(2 \%)$, lipids (2\%), and minerals $(8 \%)$. Because the sugars and organic acids account for the major portion of tomato total and soluble solids, most of the research concerning tomato quality has centered on these components.

Studies concerning the changes that occur in sugar content during the development of tomato fruit have shown that the total sugar content increases progressively throughout maturation and ripening, with accelerated accumulation associated with the first appearance of yellow pigment in the walls of the fruit at the breaker stage (Beltran and Macklin, 1962; Winsor et al., 1962).

Organic acids are not only important for the flavor of tomatoes, but also play an important part in the preservation of canned tomato products. High solids and a favorable solids : acid ratio are essential to good quality processing tomatoes (Stevens, 1972). Acid concentration must be high enough to give a $\mathrm{pH}$ of $<4.4$ to avoid problems of spoilage caused by thermophylic organisms (Rice and Pederson, 1954). The most abundant acids in ripe tomato fruits are citric and malic (Sakiyama, 1966; Stevens, 1972). From mature-green to red-ripe, fruit acidity increases to

Received for publication 1 Aug. 1991. Accented for publication 17 Aug. 1992. This research-was supported by the Illinois Agr. Expt. Sta. Urbana, as part of Hatch Project 65-0348 (JAJ). The cost of publishing this paper was defrayed in part by the payment of page charges. Under postal regulations, this paper therefore must be hereby marked advertisement solely to indicate this fact. a maximum at the appearance of yellow pigmentation, followed by a progressive decrease in acidity as ripening continues (Winsor et al., 1962). As a result of their different rates of synthesis and turnover during ripening, the malic to citric acid ratio was found to decrease rapidly throughout the development of tomato fruits (Davies, 1964, 1966; Sakiyama, 1966).

The high SSC (> 10\%) of certain wild species suggests that the genetic and physiological potential exists for developing tomatoes with enhanced SSC. Factors that may influence the solids content of tomato fruits include a high leaf area : fruit ratio, the rate of assimilate export from leaves, rate of import of assimilates by fruits, and fruit $\mathrm{C}$ metabolism (Hewitt et al., 1982). According to Walker and Ho (1977), sink strength of a tomato fruit is principally affected by the sink activity of the fruit. The major mechanisms involved in sink activity are: 1) unloading of sucrose by the phloem, 2) hydrolysis and uptake of sugars, and 3) the biosynthesis and storage of carbohydrates (Ho et al., 1983). Starch and structural materials are the primary forms of storage of imported C. Starch levels have been shown to increase in early stages of fruit development, followed by a decrease to virtually zero by ripeness due to subsequent conversion to sugars (Davies and Cocking, 1965).

Literature on the genetics of soluble solids in tomatoes indicates that this trait is quantitatively inherited. Stoner and Thompson (1966) observed heterosis in a diallele study of solids in tomatoes due to epistasis. They also observed dominance for high solids content. Ibarbia and Lambeth (1969) estimated that allelic variation at about three gene loci controlled SSC. The means of the $F_{1}$ and $F_{2}$ progeny fell very close to the mid-parent mean, suggesting additive gene action for soluble solids.

Rick (1974) was able to successfully transfer genes for high $\mathrm{SSC}$ of ripe tomato fruits from a wild green-fruited species. An increase of $2.2 \%$ in SSC was observed, a gain of $>40 \%$ over

Abbreviation: SSC, soluble solids concentration. 
that of the recurrent parent. This change was accomplished by repeated backcrossing of $L$. chimelewskii and LA 1028, a wild, green-fruited species ( $\approx 10 \% \mathrm{SSC}$ ) to L. esculentum cv. VF 36 'VF145B' ( $\approx 5 \% \mathrm{SSC}$ ) to obtain a series-of $\mathrm{BC}_{5} \mathrm{~S}_{5}$ lines, including LA 1501 and LA 1563, which possess increased SSC ( $\approx 7 \%$ to $8 \%$ ) without decreasing total yield, fruit size, or color (Rick, 1974). Rick concluded that the genetic control for the inheritance of SSC was very complex and that several loci must be involved. This material is of particular interest, since computer simulation studies have shown that repeated cycles of backcrossing and selection will generally lead to the transfer of only a few genes (five or fewer) from the donor parent (Reddy and Comstock, 1976). Based on this information, it is reasonable to assume that even though LA 1501 has significantly higher levels of SSC than 'VF 145B-7879', these differences are probably controlled by a fairly small number of genes, each with a fairly large effect on SSC.

Selection for quantitatively inherited traits with low heritabilities is very difficult. A major problem associated with the development of high-yielding tomatoes with improved quality is that there is often an inverse relationship between yield and SSC (Rick, 1974). The genetic inheritance of both of these characteristics is controlled by many genes, making it very difficult to breed for both traits simultaneously. It would, therefore, be advantageous to attempt to identify and isolate individual genes that have a major effect on tomato solids and yield. In a study by Osborne et al. (1987), two restriction fragment length polymorphisms (RFLP's) linked to genes controlling SSC in tomato fruit were identified. The plant materials used in this study were L. chimelewskii LA 1028, a wild, green-fruited species ( $\approx 10 \% \mathrm{SSC}$ ), L. esculentum cv. VF 36 ( $\approx 5 \% \mathrm{SSC}$ ), and LA 1563, a $\mathrm{BC}_{5} \mathrm{~S}_{5}$ line derived from repeated backcrossing of L. chimelewskii LA 1028 to L. esculentum cv. VF 36, which possesses a higher SSC ( $\approx 7 \%$ to $8 \%$ ). Recent studies by $\mathrm{Pa}-$ terson et al. (1988, 1990) regarding the genetic basis of quantitative variation in phenotype, using plant materials similar to those used in this study, demonstrate the first use of a complete RFLP linkage map to resolve quantitative traits into discrete Mendelian factors [quantitative trait loci (QTLs)] in an interspecific backcross of tomato. With the use of such a linkage map, Paterson et al. (1988) were able to map at least six QTLs controlling fruit mass, four QTLs for the concentration of soluble solids, and five QTLs for fruit $\mathrm{pH}$. This might indicate that there are relatively few genes located on specific chromosome segments that are controlling the level of SSC.

The purpose of this study was to ascertain which of the chemical constituents represent the major fraction of tomato total soluble solids and account for most of the difference between the high and low soluble solids parents. Since concentrations of individual components change during fruit development, it is important to determine the fruit stage where differences between the parents are greatest to optimize selection. This study will also provide a foundation for genetic and physiological studies currently in progress aimed at isolating individual genes controlling this economically important trait.

\section{Materials and Methods}

Selection and production of testing materials. The high SSC line LA 1501 and the commercial cultivar VF 145B-7879 were obtained from Charles M. Rick, Univ. of California, Davis. LA 1501 was developed from repeated backcrossing of the wild green-fruited species, L. chimelewskii (LA 1028) to L. esculentum cv. VF 145B-7879 (Rick, 1974).
Field design and samplepreparation. Seedlings of the parents and $F_{1}$ reciprocal hybrids were transplanted to the field in a randomized complete-block design in Spring 1987. Each of the four blocks consisted of 20 plants, five plants of each of the parents and the $F_{1}$ reciprocal hybrids. As the plants began to flower, individual flowers were tagged with a sample number corresponding to the date of anthesis. A sample consisted of two fruit from each of the five plants within a given block. Flowers were thinned to a maximum of three per truss.

Tagged flowers were randomly assigned a harvest date ranging from 25 to 52 days after anthesis at 3-day intervals. The fruit samples were collected on the randomly assigned harvest date, washed, and the fresh weight was recorded. The samples were then ground in a blender until homogeneous. A portion of the resultant puree was saved and frozen for subsequent dry weight and color determination. Additional puree was centrifuged in a Beckman J2-21M centrifuge (Beckman, Carlsbad, Calif.) at 10,000 rpm for $15 \mathrm{~min}$ at $10 \mathrm{C}$. The supernatant was saved and frozen for subsequent analysis of sugars, $\mathrm{pH}$, percent soluble solids, and titratable acidity.

Sample analysis. Color was measured with a Hunter Digital Color Difference Meter (Hunter Associates Laboratory, Fairfax, Va.). A 10-ml sample of pulp was placed into a small disposable petri dish and placed over the specimen port. For the purpose of this study, only the 'a' values were used, which measures greenness (when negative) or redness (when positive).

Quantification of sugars was achieved by means of high performance liquid chromatography with the aid of a Supelco LC$\mathrm{NH}$, carbohydrate analysis column $(5 \mu)$ (Supelco, Bellefonte, $\mathrm{Pa}$.) measuring $250 \times 4.6 \mathrm{~mm}$. A mobile phase of acetonitrilewater $(80: 20, \mathrm{v} / \mathrm{v})$ was used at a flow rate of $2.00 \mathrm{ml} \cdot \mathrm{min}^{-1}$. Ten microliters of the individual samples and the sugar standards were injected into the column. Concentrations of the individual sugars present in the samples were determined using a regression equation calculated from the standards.

Titratable acidity and $\mathrm{pH}$ were measured with a model 610 Fisher Accumet pH meter (Fisher Scientific, Pittsburgh.). Twenty milliliters of serum for each of the samples was thawed and brought to room temperature. The $\mathrm{pH}$ was measured for each of the samples. A 5-ml sample was removed and titrated to 8.1 with a $0.1 \mathrm{~N} \mathrm{NaOH}$ solution according to Lees (1968).

The percent dry weight of the pulp (percent total solids) and serum (percent soluble solids) was determined from $10 \mathrm{~g}$ of pulp and $5 \mathrm{~g}$ of serum, respectively. Samples were pipeted into preweighed 20-ml vials, frozen and freeze dried for $72 \mathrm{~h}$ in a Virtis Freezemobile 3 (Virtis Co., Gardiner, N.Y.). Dried samples were then reweighed to calculate the percent dry weight.

\section{Results}

Color. Because there is a very high correlation between the development of lycopene and the maturity of the fruit (Table 1), the accumulation of all the other components measured was expressed in values of 'a' using the Hunter Color Difference Meter. Quantitative measurement of fruit color is a physiological measurement of the actual developmental age of the fruit and changes in most of the chemical constituents of the fruit were found to regress linearly with changes in fruit color.

Fruit color development was measured at 3-day intervals from 25 to 52 days after anthesis for each of the parents and the reciprocal $F_{1}$ hybrids. In general, there was a gradual increase in 'a' until breaker (corresponding roughly to 0 on the Hunter scale) due to a decrease in green coloration. This decrease was followed by a dramatic increase in red coloration, throughout 
Table 1. Correlation matrix for the components of total solids over all genotypes.

\begin{tabular}{|c|c|c|c|c|c|c|c|c|c|}
\hline & $\begin{array}{r}\text { Dry } \quad \text { wt } \\
\text { pulp }(\%)\end{array}$ & $\begin{array}{c}\text { Dry wt } \\
\text { serum }(\%)\end{array}$ & $\begin{array}{c}\text { Fructose } \\
(\%)\end{array}$ & $\begin{array}{c}\text { Glucose } \\
(\%)\end{array}$ & $\begin{array}{l}\text { Total } \\
\text { sugar } \\
\end{array}$ & $\begin{array}{c}\text { Hunter } \\
\text { "a" }\end{array}$ & $\mathrm{pH}$ & $\begin{array}{c}\text { Citrate } \\
(\%) \\
\end{array}$ & $\begin{array}{l}\text { Days to } \\
\text { harvest }\end{array}$ \\
\hline Dry weight pulp (\%) & & $0.1786 * *$ & $-0.0335 \mathrm{NS}$ & $0.3426 * * *$ & $0.1598 * *$ & $-0.3809 * * *$ & $0.5412 * * *$ & $-0.2957 * * *$ & $-0.4670 * * *$ \\
\hline Dry wt serum $(\%)$ & --- & & $0.5109 * * *$ & $0.5544 * * *$ & $0.5719 * * *$ & $0.2975 * * *$ & $-0.0646 \mathrm{NS}$ & $0.2642 * * *$ & $0.2242 * * *$ \\
\hline Fructose $(\%)$ & -- & -- & & $0.7301 * * *$ & $0.9346 * * *$ & $0.4643 * * *$ & $-0.2721 * * *$ & $0.2256 * * *$ & $0.4115^{* * *}$ \\
\hline Glucose $(\%)$ & -- & -- & -- & & $0.9254 * * *$ & $-0.0421 \mathrm{NS}$ & $0.2021 * * *$ & $-0.0230 \mathrm{NS}$ & $-0.1043 \mathrm{NS}$ \\
\hline Total sugar $(\%)$ & --- &.- & -- & -- & & $0.2355 * * *$ & $-0.0457 \mathrm{NS}$ & $0.1131 *$ & $0.1739 * *$ \\
\hline Hunter "a" & -- &.- & -- & $-\cdot-$ & -- & & $-0.5971 * * *$ & $0.4148 * * *$ & $0.8995 * * *$ \\
\hline $\mathrm{pH}$ & -- & -- & --- & --- & --- & --- & & $-0.8129 * * *$ & $-0.7223 * * *$ \\
\hline Citrate $(\%)$ & -- & $\cdots$ & $\cdots$ &.- & --- & -- & $-\cdots$ & & $0.5122 * * *$ \\
\hline Days to harvest & -- & --- & $\cdots$ & -- & --- & -- & -- & $\cdots$ & \\
\hline
\end{tabular}

*******Significant at $0.01<P<0.05,0.001<P<0.01$, or $0.0001<P<0.001$, respectively. NS $=$ nonsignificant.

the ripening of the fruit, associated with the rapid increase in lycopene synthesis following the climacteric (Fig. 1). The parents and the reciprocal $F_{1}$ hybrids all followed the same pattern of development of pigmentation.

Total solids. The percent dryweight is a measure of the total solids, consisting of the water soluble and insoluble solids. The percent dry matter decreased for all genotypes throughout maturation of the fruit when expressed on a fresh weight basis (Fig. 2). LA 1501 had the highest percent dry weight and 'VF 145B7879' the lowest (Table 2). There were essentially no differ-

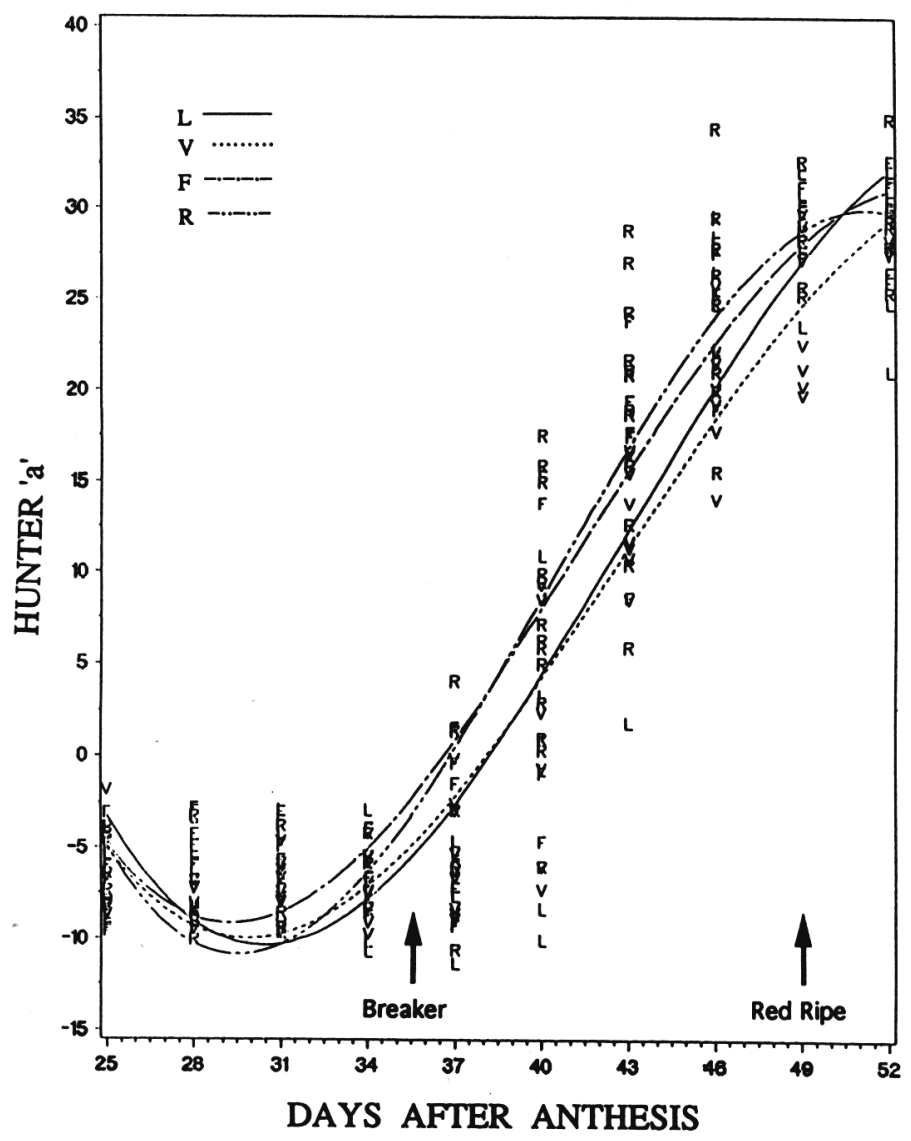

Fig. 1. Changes in fruit color from 25 to 52 days after anthesis (DA) for LA 1501 (L), 'VF 145-7879' (V), LA $1501 \times$ 'VF 145-7879' $(\mathrm{F})$, and 'VF $145-7879$ ' $\times$ LA $1501(\mathrm{R})$. The regression equations for the four genotypes are L: $366.28-30.538 \mathrm{DA}+0.785 \mathrm{DA}^{2}$ - $0.0062 \mathrm{DA}^{3}, \mathrm{~V}: 248.10-20.755 \mathrm{DA}+0.525 \mathrm{DA}^{2}-0.0040$ $\mathrm{DA}^{3}, \mathrm{~F}: 370.79-31.812 \mathrm{DA}+0.843 \mathrm{DA}^{2}-0.0069 \mathrm{DA}^{3}$, and $\mathrm{R}: 408.27-34.915 \mathrm{DA}+0.926 \mathrm{DA}^{2}-0.0076 \mathrm{DA}^{3}$.

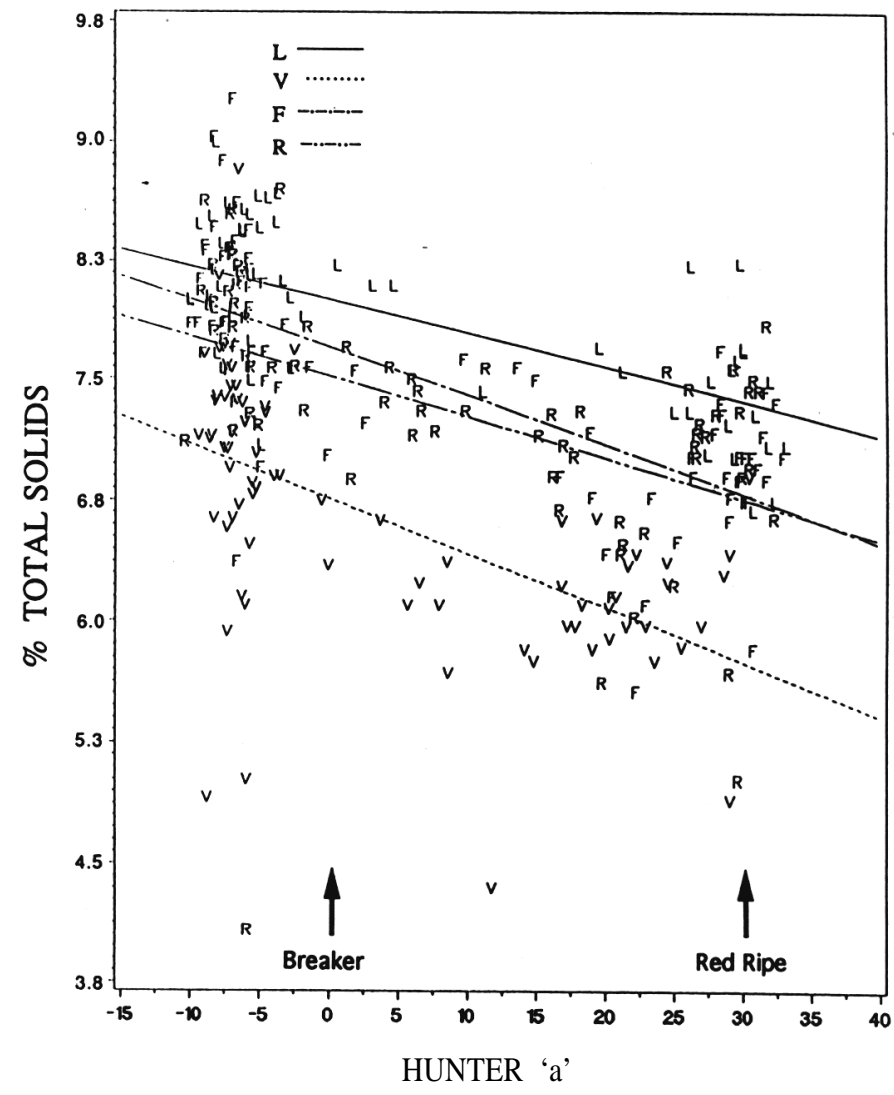

Fig. 2. Changes in the total solids concentration for LA 1501 (L), 'VF 145-7879' (V), LA $1501 \times$ 'VF 145-7879' (F), and 'VF 145$7879 \times$ LA $1501(\mathrm{R})$ as the fruit matures from the immature-green stage ("a" = - 10) to the red-ripe stage ("a" = 30). The regression equations for the four genotypes are L: $10.65-0.028 \mathrm{~A}, \mathrm{~V}$ : $8.87-0.039 \mathrm{~A}, \mathrm{~F}: 10.21-0.048 \mathrm{~A}$, and $\mathrm{R}: 10.01-0.033 \mathrm{~A}$.

ences between the reciprocal $F_{1}$ hybrids. The percent dry matter for both of the hybrids was intermediate between the two parents when red-ripe (Hunter ' $a$ ' $=30$ ), although the concentrations around the immature-green stage (Hunter ' $a$ ' $=-5$ ) were much closer to that of LA 1501, indicating possible dominance for some component of total solids. This decrease in the percent total solids presumably is due to a dilution in concentration resulting from fruit water uptake during ripening. An analysis of the accumulation of total solids on a dry weight basis (results not shown) supported this assumption. This result suggests that the parents may differ genetically with respect to the water content of the fruit. Dinar and Stevens (1981) reported that LA 


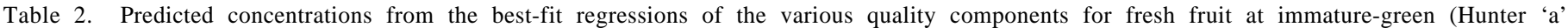
$=-5$ ) and red-ripe (Hunter ' $a$ ' $=30$ ).

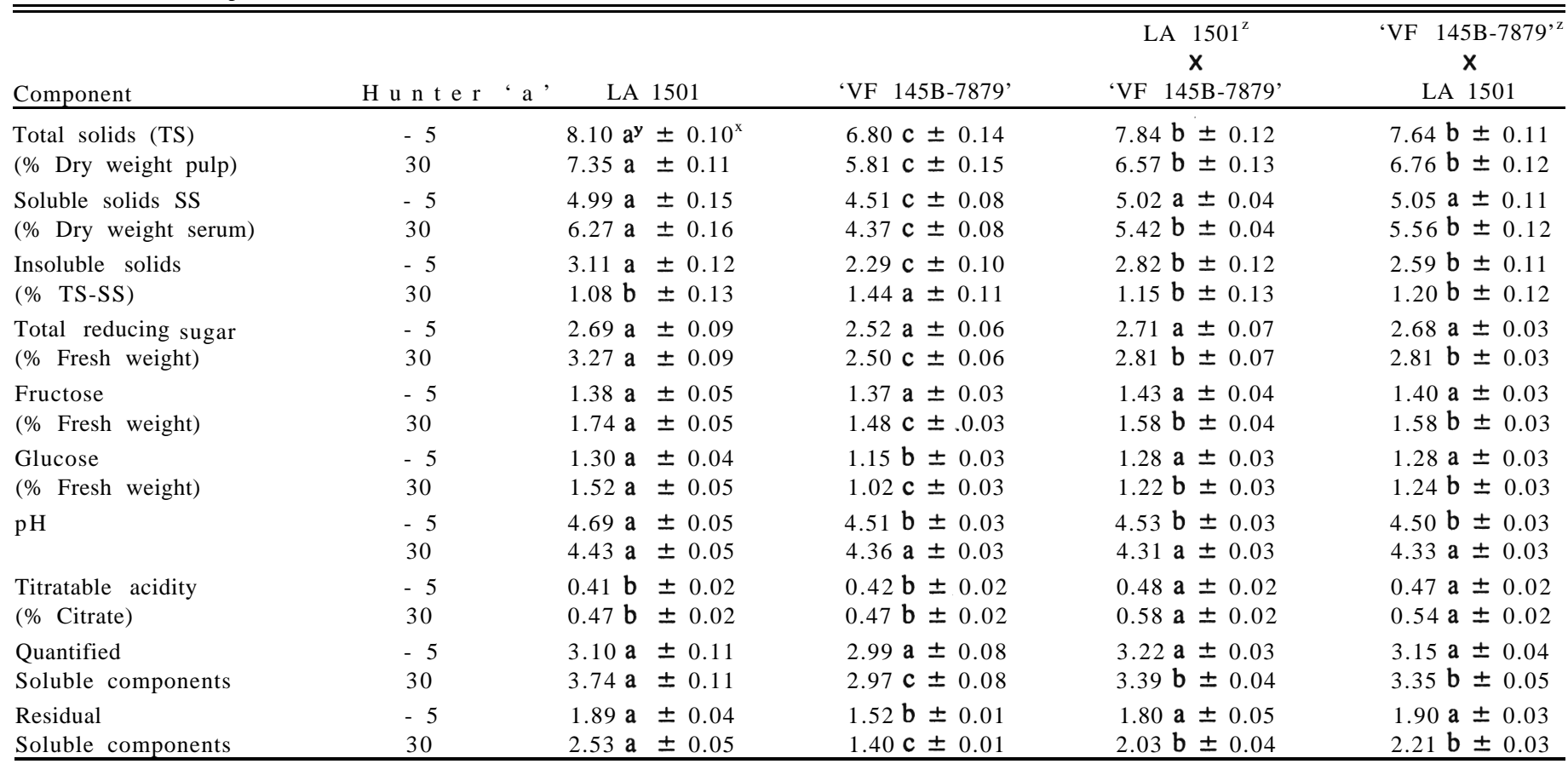

${ }^{\mathrm{z}}$ Female parent of the cross.

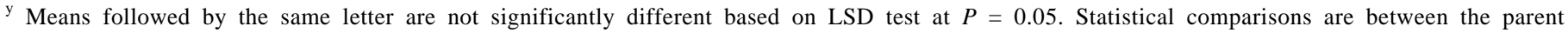
and $F_{1}$ genotypes at the same maturity.

$\mathrm{x}$ The $95 \%$ confidence interval for the predicted value.

1563, a high soluble solids genotype (Rick, 1974), had a significantly higher solids concentration than 'VF145B-7879' from 10 days after anthesis to maturity. The total solids content at 50 days after anthesis was reported as $7.08 \%$ and $6.15 \%$ for LA 1563 and 'VF145B-7879', respectively. Hewitt et al. (1982) determined that LA 1563 had a greater sink strength for assimilates than 'VF145B-7879'. Studies have indicated that the rate of fruit metabolism influences the sink strength of the fruit for photosynthates (Hewitt et al. 1982; Walker and Ho, 1977). The concentration of the reducing sugars in the fruit of LA 1563 has been shown to be correlated with increased starch levels and greater activities of the enzymes ADPglucose pyrophosphorylase (EC 2.7.7.27) and sucrose synthase (EC 2.4.1.13) (Robinson et al., 1988). A higher metabolic rate and greater uptake of assimilates by LA 1501 during the maturation of the fruit would result in a lower fruit osmotic potential. The more negative the fruit osmotic potential the greater the uptake of water. This process may partially explain the variation and differences in fruit solids and reducing sugars on a dry and fresh weight basis.

Soluble solids (dry weight basis). The percent dry weight of the serum is a measure of the solids present in the water soluble fraction of the fruit puree. There was a linear change in SSC for all genotypes when expressed in terms of Hunter ' $a$ ' on a fresh weight basis (Fig. 3). Differences between previous reports of dramatic changes associated with the climacteric occurring around the breaker stage of development are accounted for by the expression of SSC on the basis of Hunter ' $a$ '. This relationship is obvious when looking at the distribution of samples, where a large cluster of samples fall around Hunter ' $a$ ' $=-5$, indicating that few changes are occurring before the breaker stage.

The high soluble solids line, LA 1501, increased $1.28 \%$ in SSC from immature-green to red-ripe, whereas 'VF 145B-7879' showed a decrease of $0.14 \%$. The reciprocal $F_{1}$ hybrids had an initial concentration not significantly different from that of LA 1501, whereas that of 'VF 145B-7879' was significantly lower. At red-ripe, the hybrids showed levels intermediate between the two parents, indicating an additive effect associated with the inheritance of SSC as a whole.

In LA 1501, the soluble solids accounted for roughly $62 \%$ of the total solids at immature-green and $85 \%$ at red-ripe, an increase of $24 \%$ (Table 2). In 'VF 145B-7879', the soluble solids accounted for $\approx 66 \%$ of the total solids at immature-green and $75 \%$ at red-ripe, an increase of only $9 \%$. This difference indicates that, although LA 1501 has a similarly low soluble solids : total solids ratio at the immature-green stage, as the fruit ripens, this ratio increases at a substantially higher rate than for 'VF 145B-7879'.

Sugars. The only sugars present in the tomato lines analyzed were fructose and glucose, and, in general, the percentage of fructose was slightly higher than that of glucose. Both the parents and the hybrids showed a linear response in relation to the accumulation of sugars (percent fresh weight) when expressed in terms of Hunter ' $a$ ' (Fig. 4). The total sugar concentration for LA 1501 increased sharply from immature-green to red-ripe, which is to be expected since both percent fructose and glucose were found to increase as the fruit ripened (Fig. 4). Although LA 1501 had the highest final concentration of sugar at the initial stages of development, there were no significant differences between any of the genotypes. LA 1501 had a final sugar concentration $24 \%$ higher than the commercial cultivar, as cornpared to an increase of $11 \%$ in the hybrids (Table 2). There were no significant differences between the $F_{1}$ hybrid and the reciprocal cross, and the concentration of sugars increased slightly throughout fruit ripening. This pattern can be explained by the 


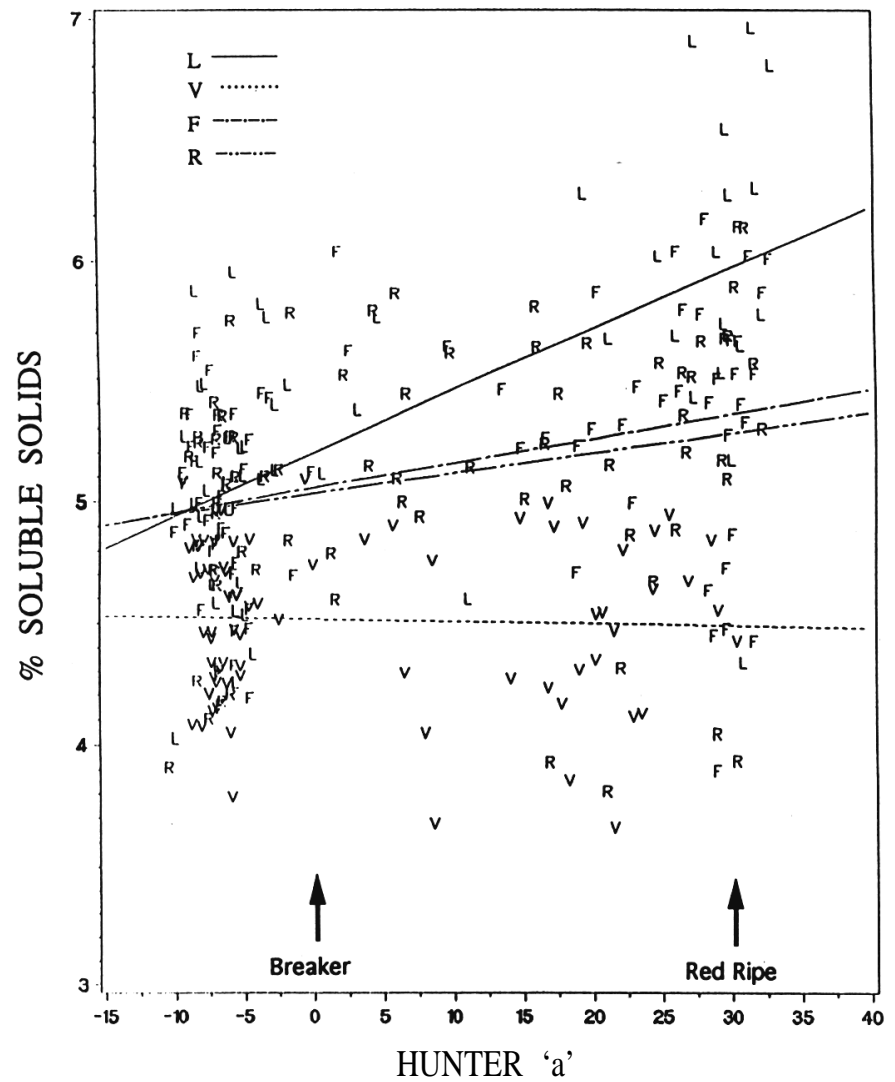

Fig. 3. Changes in the SSC for LA 1501 (L), 'VF 145B-7879' (V), LA $1501 \times$ 'VF 145B-7879' (F), and 'VF 145B-7879' x LA 1501 $(\mathrm{R})$ as the fruit matures from the immature-green stage ("a" = -10) to the red-ripe stage ("a" = 30). The regression equations for the four genotypes are L: $5.15-0.032 \mathrm{~A}, \mathrm{~V}: 4.49-0.004 \mathrm{~A}$, F: $5.06-0.008 \mathrm{~A}$, and R: $5.09-0.008 \mathrm{~A}$.

fact that as the concentration of fructose increased, there was a corresponding decrease in the glucose concentration. Although there was no net increase in the percent total sugars, the final concentration was intermediate between the two parents, indicating an additive effect in relation to the accumulation of sugar and/or uptake of water into the fruit.

In 'VF 145B-7879', the total sugar concentration (percent fresh weight) decreased slightly as the fruit developed from immature-green to red-ripe (Fig. 4). This decrease is a result of a low rate in the accumulation of fructose being offset by a slightly greater decrease in the accumulation of glucose. This slight decrease in the percent total sugars is probably due to a dilution in concentration resulting from fruit water uptake. A positive accumulation of glucose was observed when concentrations were calculated on a dry weight basis (results not shown). In the high soluble solids parent, it is evident that the rates of accumulation for both fructose and glucose are higher than the rate of water uptake, resulting in the net increase in the percent total sugars throughout ripening.

$p H$. The $\mathrm{pH}$ decreased dramatically from the immature-green through the breaker stage. After breaker stage, $\mathrm{pH}$ was observed to increase through the red-ripe stage for both of the parents and the hybrids (Fig. 5). LA 1501 had a higher $\mathrm{pH}$ throughout ripening than did 'VF 145B-7879'. Fruit $\mathrm{pH}$ for both of the $\mathrm{F}_{1} \mathrm{~s}$ was similar to that of 'VF 145B-7879'. This dominance for high acidity is in marked contrast to the additive gene action seen in the accumulation of sugars.

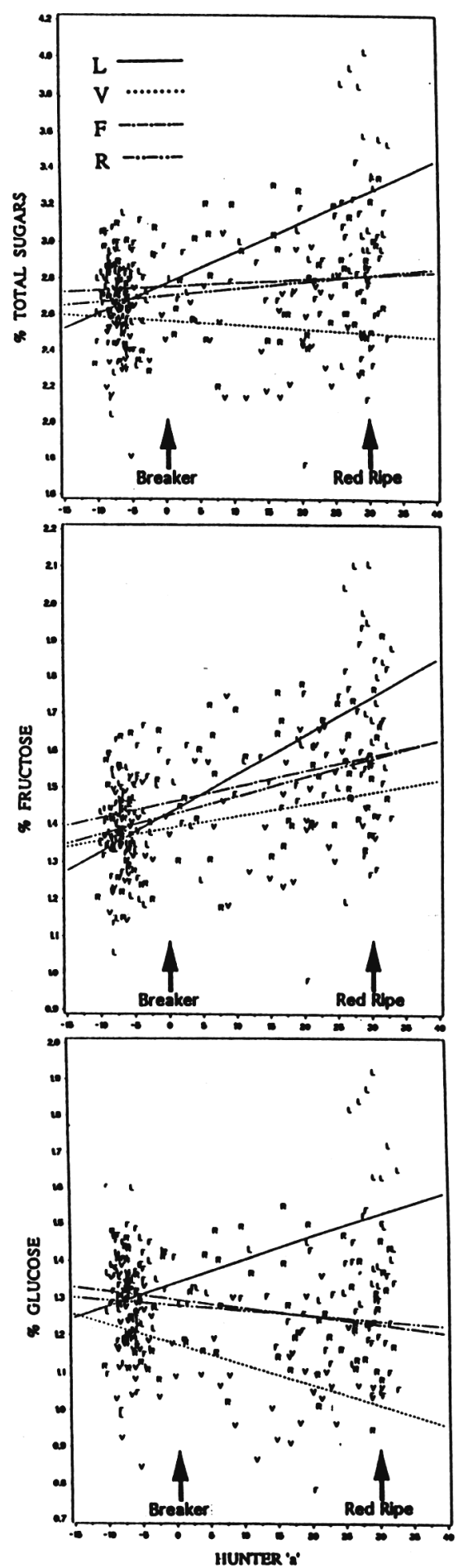

Fig. 4. Changes in the total sugar (top), fructose (middle), and glucose (bottom) concentration for LA 1501 (L), 'VF 145-7879' (V). LA 1501 × 'VF 145-7879' (F), and 'VF 145:7879' x LA 1501 (R) as the fruit matures from the immature-green stage ("a" $=-10)$ to the red-ripe stage ("a" $=30$ ). The regression equations for the four genotypes for total sugar are L: $2.77+0.017 \mathrm{~A}, \mathrm{~V}: 2.56-$ $0.002 \mathrm{~A}, \mathrm{~F}: 2.75+0.002 \mathrm{~A}$, and R: $2.70+0.004 \mathrm{~A}$, for fructose are L: $1.43+0.011 \mathrm{~A}, \mathrm{~V}: 1.38+0.003 \mathrm{~A}, \mathrm{~F}: 1.45+0.004 \mathrm{~A}$, and R: $1.42+0.005 \mathrm{~A}$; and for glucose are L: $1.33+0.006 \mathrm{~A}$, V: $1.17+0.005 \mathrm{~A}, \mathrm{~F}: 1.29+0.002 \mathrm{~A}$, and R: $1.28+0.001 \mathrm{~A}$.

Titratable acidity. The relationship between $\mathrm{pH}$ and titratable acidity was inverse. For the parents and the hybrids, the titratable acidity increased from the immature-green through the breaker 


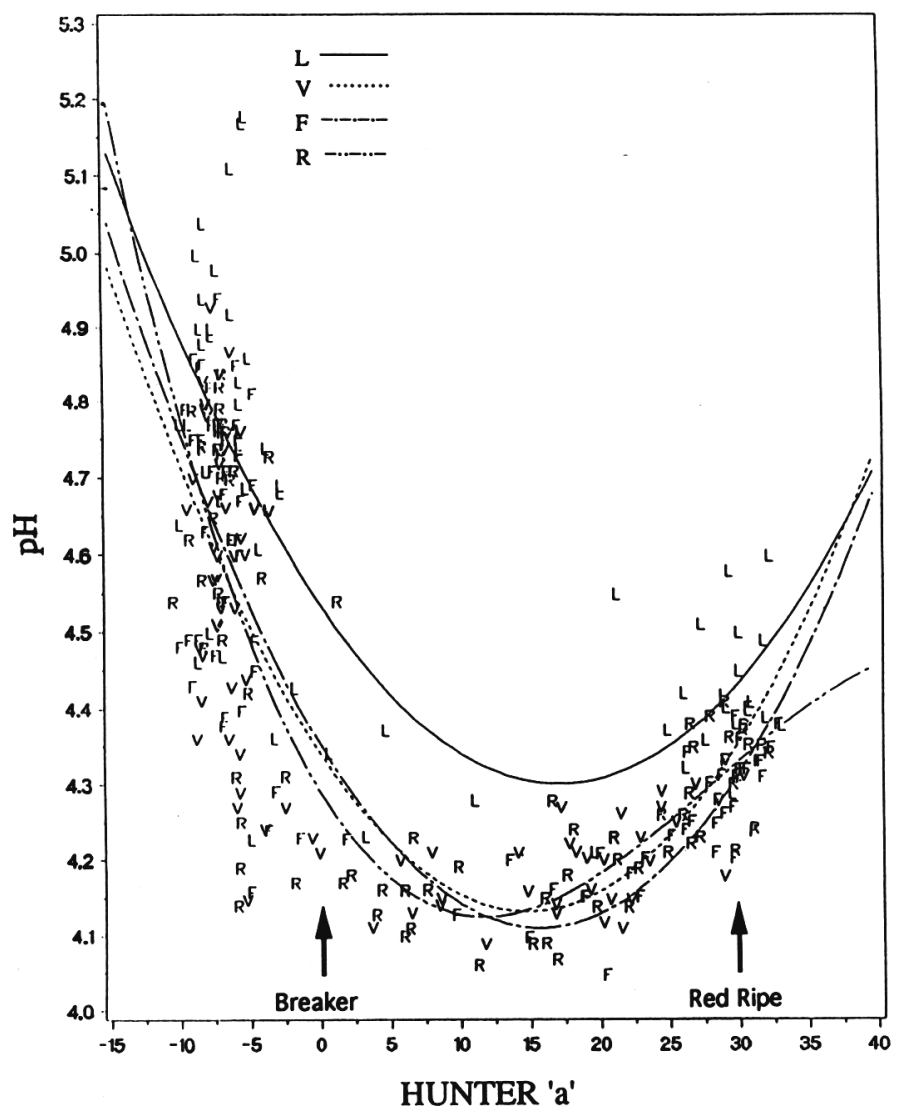

Fig. 5. Changes in the pH for LA 1501 (L), 'VF 145-7879 (V), LA $1501 \times$ 'VF 145-7879' (F), and 'VF 145-7879' $\times$ LA $1501(\mathrm{R})$ as the fruit matures from the immature-green stage ("a" = - 10) to the red-ripe stage ("a" $=30$ ). The regression equations for the four genotypes are L: $4.53-0.027 \mathrm{~A}+0.00081 \mathrm{~A}^{2}, \mathrm{~V}: 4.34-0.029 \mathrm{~A}$ $+0.00097 \mathrm{~A}^{2}, \mathrm{~F}: 4.35-0.031 \mathrm{~A}+0.00099 \mathrm{a}^{2}$, and R: $4.29-$ $0.31 \mathrm{~A}+0.00167 \mathrm{~A}^{2}-0.00002 \mathrm{~A}^{3}$.

stage, followed by a decrease up to the red-ripe stage (Fig. 6). LA 1501 possessed the lowest rate of citrate accumulation, although the concentration was not significantly different than for 'VF 145B-7879'. The reciprocal $\mathrm{F}_{1}$ hybrids had significantly higher citrate concentrations than either of the parents, which indicates that heterosis is involved in the inheritance of organic acids (Table 2).

Partitioning of components. To determine the source of variation between the parents, changes in the partitioning of the components over the period of fruit development were evaluated. Soluble solids accounted for anywhere from $61.6 \%$ of the total solids at immature-green to $85.3 \%$ at red-ripe (Table 2). The ratio percent soluble : total solids increased $23.7 \%$ in LA 1501 from immature-green to red-ripe compared to an increase of only $8.9 \%$ in 'VF 145B-7879'. The SSC was further subdivided into the quantified components (percent sugar + percent acid) and residual components (percent SSC minus percent quantified components). In LA 1501, the ratio of quantified components : total solids increased $12.6 \%$ throughout ripening compared to an increase of $11.1 \%$ for the residual fraction. However, for 'VF 145B-7879', the quantified components increased $7.2 \%$, while the residual components increased only $1.8 \%$. This difference indicates that some component(s) of the soluble solids other than the sugars and acids are accounting for a significant proportion of the differences between the parents.

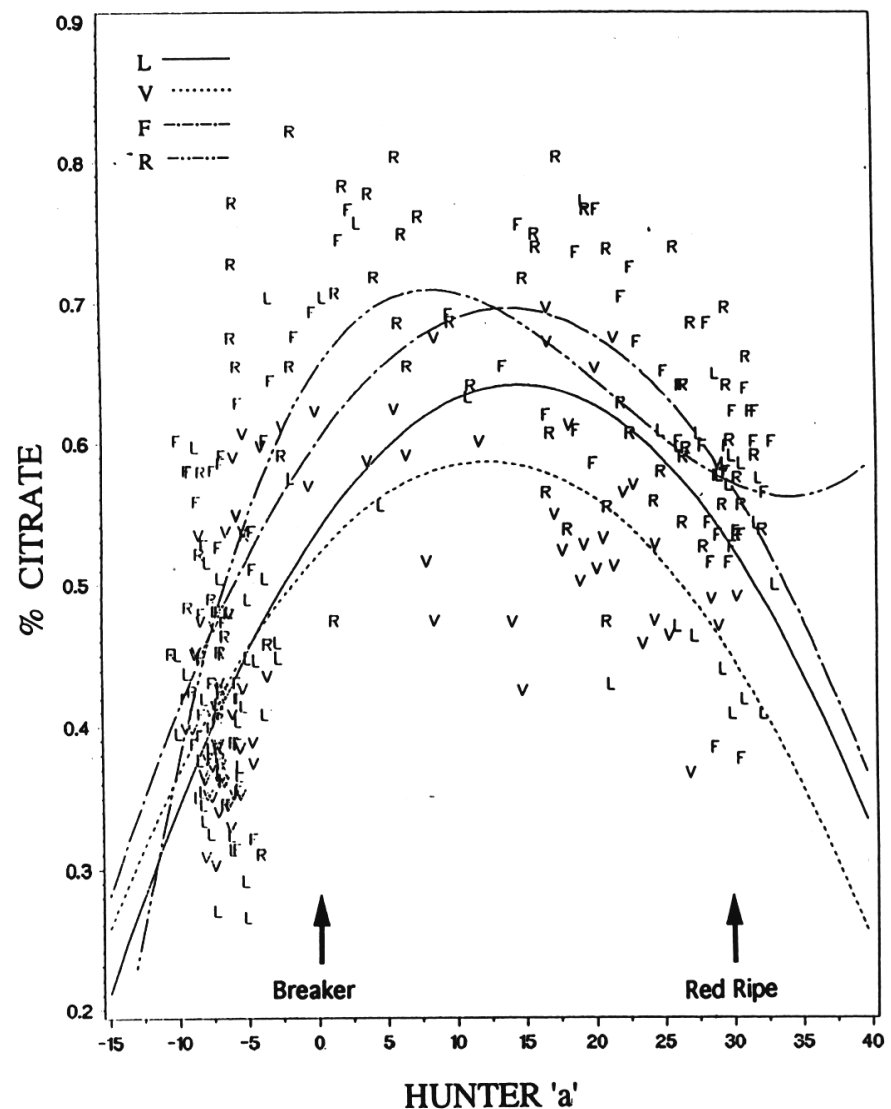

Fig. 6. Changes in the titratable acidity, expressed as the equivalent in percent citrate, for LA 1501 (L), 'VF 145-7879' (V), LA $1501 \times$ 'VF 145-7879' (F), and 'VF 145-7879' x LA 1501 (R) as the fruit matures from the immature-green stage ("a" = - 10) to the redripe stage ("a" $=30)$. The regression equations for the four genotypes are L: $0.49+0.013 \mathrm{~A}-0.0005 \mathrm{~A}^{2}, \mathrm{~V}: 0.48+0.010 \mathrm{~A}+$ $0.0004 \mathrm{~A}^{2}, \mathrm{~F}: 0.56+0.013 \mathrm{~A}-0.0005 \mathrm{~A}^{2}$, and $\mathrm{R}: 0.54+0.012 \mathrm{~A}$ $-0.0004 \mathrm{~A}^{2}+\left(1.36 \times 10^{-7}\right) \mathrm{A}^{3}$.

\section{Discussion}

This study was designed to identify possible causes for differences in the accumulation of the soluble and insoluble solids for two tomato genotypes and their reciprocal $F_{1}$ hybrids throughout fruit development. Several earlier studies (Beltran and Macklin, 1962; Winsor et al., 1962) have reported pronounced increases in the soluble solids associated with the first appearance of yellow pigment in the walls of the fruit. We have shown that expressing the accumulation of the various components measured in terms of Hunter ' $a$ ' simplified the results by providing a linear relationship for all the components except $\mathrm{pH}$ and percent citrate. This finding suggests that quantitative changes in fruit color are a superior indicator of the actual developmental age of the fruit rather than days after anthesis. The greatest differences between the parents in the concentrations of the components measured occurred at red-ripe, suggesting that the best stage to select for increased soluble solids in tomato fruit would be at red-ripe.

The percent dry matter decreased for all the genotypes throughout the maturation of the fruit when expressed on a fresh weight basis. This decrease in the percent total solids presumably is due to respiration and a dilution in concentration resulting from fruit water uptake. LA 1501 had the highest percent 
dry weight, whereas 'VF 145B-7879' had a lower concentration (Table 2). The higher value for total solids present in LA 1501 is associated mainly with increased SSC, possibly due to increased sink strength (Hewitt et al., 1982).

Of the two sugars quantified, glucose accounted for a greater proportion of the differences between the parents at the red-ripe stage. Although the differences between the parents were significant for both sugars, the difference in glucose concentration between LA 1501 (1.52\%) and 'VF 145B-7879' (1.02\%) was $0.50 \%$, a difference of almost twice that observed for fructose $(0.26 \%)$.

Results from this study indicate that although LA 1501 has a lower soluble solids : total solids ratio at the immature-green stage, as the fruit ripens this ratio increases at a substantially higher rate than for 'VF 145B-7879'. One possible explanation for these differences between the parents might be attributed to an increased level of starch in LA 1501 at the immature-green stage. Although starch was not measured in this study, Dinar and Stevens (1981) reported that a high rate of starch accumulation during the early stages of fruit development contributes to an increase in hexose levels in the ripe fruit. In their study, they compared the relationship between starch accumulation and SSC for several cultivars and a high SSC line (LA 1563) that is genetically similar to LA 1501. They observed that the starch concentration 28 days after anthesis was significantly higher for LA 1563 than for the other genotypes. The starch concentration was negatively associated with the hexose levels measured at the same time. However, the total SSC of the ripe fruits was found to be positively associated with the starch content at 28 days after anthesis. This result might partially explain the significantly higher solids fraction observed in LA 1501 at immature-green.

Based on the partitioning information, we can speculate on the chemical constituents responsible for differences in SSC between the two parents. Although the sugars and acids account for the majority of the total solids, the variation in the quantified soluble components/total solids between the two parents at redripe was only $0.2 \%$ ( $51.1 \%$ for 'VF $145 \mathrm{~B}-7879$ ' and $50.9 \%$ for LA 1501). When making similar comparisons for the residual soluble fraction, the difference was $10.3 \%$ (24.1\% for 'VF 145B7879' and $34.4 \%$ for LA 1501). This result clearly indicates that components of the soluble solids besides sugars and acids are having a significant effect on the accumulation of fruit dry matter in the high soluble solids parent. On the basis of previous reports, this fraction probably is composed primarily of pectin or soluble starch or possibly other components such as amino acids, lipids, and minerals (Davies and Hobson, 1981). Based on these findings, a more complete analysis of the water soluble components must be carried out to identify the chemical constituent(s) responsible for these differences.

Concentrations of total solids, soluble solids, fructose, and glucose throughout fruit ripening for the reciprocal $F_{1}$ hybrids were intermediate to the two parental lines indicating additive trait inheritance, while dominance was observed for $\mathrm{pH}$ and titratable acidity (percent citrate). These differences in the modes of inheritance among the various chemical components of solids is indicative of the difficulties of breeding for this quantitative trait by selection for total or soluble solids.

\section{Literature Cited}

Beltran, E.G. and K.E. Macklin. 1962. On the chemistry of the tomato and tomato products. A review of the literature (1945-1961), Thomas J. Lipton, Hoboken, N.J.

Davies, J.N. 1964, 1965. The effect of variety on the malic and citric acid content of tomato fruit. Annu. Rept. Glasshouse Crops Res. Inst. 139.

Davies, J.N. 1966. Changes in the non-volatile organic acids of tomato fruit during ripening. J. Sci. Food Agr. 17:396-400.

Davies, J.N. and E.C. Cocking. 1965. Changes in the carbohydrates, proteins and nucleic acids during cellular development in tomato fruit locule tissue. Planta. 67:242-246.

Davies, J.N. and G.E. Hobson. 1981. The constituents of tomato fruitthe influence of environment, nutrition and genotype. CRC Crit. Rev. Food Sci. Nutr. 15:205-280.

Dinar, M. and M.A. Stevens. 1981. The relationship between starch accumulation and soluble solids content of tomato fruits. J. Amer. Soc. Hort. Sci. 106:415-418.

Hewitt, J.D., M. Dinar, and M.A. Stevens. 1982. Sink strength of fruits of two tomato genotypes differing in total fruit solids content. J. Amer. Soc. Hort. Sci. 107:896-900.

Ho, L.C., V. Sjut, and G.V. Hoad. 1983. The effect of assimilate supply in fruit growth and hormone level in tomato plants. Plant Growth Regulat. 1:155-171.

Ibarbia, E.A. and V.N. Lambeth. 1969. Inheritance of soluble solids in a large/small-fruited tomato cross. J. Amer. Soc. Hort. Sci. 94:496-498.

Lees, R. 1968. Laboratory handbook of methods of food analysis. Leonard Hill Books, Great Britain.

Osborne, T.C., D.C. Alexander, and J.F. Forbes. 1987. Identification of restriction fragment length polymorphisms linked to genes controlling soluble solids in tomato fruit. Theor. Applied Genet. 73:350-356.

Paterson, A.H., E.S. Lander, J.D. Hewitt, S. Peterson, S.E. Lincoln, and S.D. Tanksley. 1988. Resolution of quantitative traits into Mendelian factors, using a complete linkage map of restriction fragment length polymorphisms. Nature 335:721-726.

Paterson, A.H., J.W. Deverna, B. Lanini, and S.D. Tanksley. 1990. Fine mapping of quantitative trait loci using selected overlapping recombinant chromosomes, in an interspecies cross of tomato. Genetics 124:735742.

Reddy, B.V.D. and R.E. Comstock. 1976. Simulation of the backcross breeding method. I. Effects of heritability and gene number on the fixation of desired alleles. Crop Sci. 16:825-829.

Rice, A.C. and C.S. Pederson.. 1954. Chromatographic analysis of organic acids in canned tomato juice, including the identification of pyrrolidonecarboxylic acid. Food Res., 19, 106.

Rick, C.M. 1974. High soluble-solids content in large-fruited tomato lines derived from a wild green-fruited species. Hilgardia 42:493-510.

Robinson, N.L., J.D. Hewitt, and A.B. Bennett. 1988. Sink metabolism in tomato fruit. 1. Developmental changes in carbohydrate metabolizing enzymes. Plant Physiol. 87:727-730.

Sakiyama, R. 1966. Changes in the acid contents of tomato fruits during development. J. Jpn. Soc. Hort. Sci. 35:36-39.

Stevens, M.A. 1972. Citrate and malate concentration in tomato fruits: Genetic control and maturational effects. J. Amer. Soc. Hort. Sci. 97:655668.

Stevens, M.A., A.A. Kader, and M. Albright-Houlton. 1977. Intercultivar variation in composition of locular and pericarp portions of fresh market tomatoes. J. Amer. Soc. Hort. Sci. 102:689-692.

Stoner, A.K. and A.E. Thompson. 1966. A diallele analysis of solids in tomatoes. Euphytica 15:377-382.

Walker, A.J. and L.C. Ho. 1977. Carbon translocation in the tomato: Carbon import and fruit growth. Ann. Bot. 41:813-823.

Winsor, G.W., J.N. Davies, and D.M. Massey. 1962. Composition of tomato fruit. III. Juices from whole fruit and locules at different stages of ripeness. J. Sci. Food Agr. 13:108-115. 